\title{
End-user satisfaction of technology-enabled assessment in higher education: A coping theory perspective
}

\author{
K. R. Pillai ${ }^{1}$ (D) Pallavi Upadhyaya ${ }^{1}$ (1) - Ashish Viswanath Prakash ${ }^{2}$ (D) \\ Badrinarayan Srirangam Ramaprasad ${ }^{3}$ (I) $\cdot$ H. V. Mukesh $^{4}$ (I) $\cdot$ Yogesh Pai $^{1}$ (i)
}

Received: 30 May 2020 / Accepted: 25 November 2020/ Published online: 21 January 2021

(C) The Author(s) 2021

\begin{abstract}
The current study examines students' coping process of a forced technological intervention in academic outcome assessment in a higher education setting. A mixedmethod approach was used to study 246 post-graduate students' post-usage behaviour of electronic tablet-PC exams and examined their end-user satisfaction. This is an empirical study grounded in the Coping Model of User Adaptation (CMUA). Respondents of the study comprise of post-graduate students, who were exposed to an innovative digital device for writing descriptive exams as a substitute to the conventional paper-mode exam. Data were analyzed using SPSS and Nvivo. Findings indicate that problem-focused coping has a significant influence on end-user satisfaction, and on the contrary emotion-focused coping is insignificant among the students. The study offers insights into those institutions, which are aspiring to advance with similar interventions in academic outcome assessment. The study contributes to the literature on technostress, coping strategy, and end-user satisfaction of ICT.
\end{abstract}

Keywords Coping strategy · End-user satisfaction · Technology-enabled assessment • Technology in higher education · Technostress

\section{Introduction}

The infusion of technology into education has brought about groundbreaking innovations in learning and assessment processes across the world. Spillovers of technological innovation have bestowed many path-breaking contributions in the field of education. Leveraging computers and Internet of things, technology has displayed its seamless capabilities to take over the examination process as well. Though the use of technology

K. R. Pillai

kr.pillai@manipal.edu

Extended author information available on the last page of the article 
is not new in the process of conducting examinations, its use in high stake examination is in a nascent stage. A high-stake examination has its primacy in evaluating the magnitude of academic performance and learning outcomes. Rouseff-Baker and Holm (2004) posit that assessments provide students with information on learning goals and strategies. The primary assessment method used in higher education institutes has predominantly been pen and paper tests (Alquraan 2014; Frank and Barzilai 2004). This has been a traditionally preferred assessment method as it allows the faculty to assess a wide variety of skills of students (Denton et al. 2008). With the increased use of technology-enabled learning, several higher education institutes are using technology-enabled assessments to implement an expeditious and efficient assessment process. Studies have reiterated the primacy of computerization of the assessment process as an indispensable pre-requisite of educational advancement (Bennett 2006; Chan 2018; Dermo 2009; Hillier and Fluck 2013; Siozos et al. 2009; Thelwall 2000).

Technology-based assessment is introduced in higher education settings in a mandatory environment. Computer-based assessments have been popular recently and can be used for formative and summative assessments. When used for formative assessment, they provide students the opportunity to practice, with appropriate feedback (Admiraal et al. 2020). Technology-based assessment can induce stress on students (Gotlib et al. 2015) based on their perceptions about the technology and their level of competence using digital devices. Stress may stem due to fear of poor performance in exams and health concerns of increased exposure to electronic devices. Stress is inherent when individuals are exposed to an unfamiliar event or with similar experience in the past, with which the subjects cannot evade the exposure. Instead of surmounting the stressors, they attempt to face it by adapting to it using appropriate coping methods. Lazarus and Folkman (1984) have categorized the coping methods as problem-focused and emotion-focused.

Prior studies posit that problem and emotion-focused coping methods are not mutually exclusive (Bhattacherjee et al. 2018; Marakhimov and Joo 2017). Individuals often rely on both the coping methods and use mixed adaptation strategies to deal with the event (Lin 2016). Lazarus and Folkman (1984) argue that coping method is conditioned by how the subjects discern and decipher the stressors. Fadel (2012a) also has found evidence of how the appraisal of a challenging situation may enable individuals to adopt coping methods. When something coerced upon, wherein the subjects can neither resist nor withdraw, the only option is to adapt and adjust. Coping is the process of responding such disruptive external stimuli (Folkman 1992; Hou 2012). Recent research studies (Groomes and Leahy 2002; Marakhimov and Joo 2017) have also reported similar findings in different contexts. Previous studies (Ball and Levy 2008; Hu et al. 2003) have contemplated the need for investigating the ability of students to cope with technological intervention and their adoption.

In this backdrop, the current study investigated the factors influencing the satisfaction of students who were exposed to institutionally mandated tablet PC-based exams. Building on Hou (2012), the study construed that the magnitude and duration of computer usage directly influence students' satisfaction. The coping theory has been a fertile source of scholarly investigation to understand the relationship between coping strategies and job satisfaction in various professional fields (see, for example, Abouserie 1996; Griffith et al. 1999; Harzer and Ruch 2015; Healy and McKay 2000; Long 1993; Sequeira 2013). We used coping theory to understand how students 
adapt to externally coerced upon examination environment. The use of coping theory helped us comprehend the relative importance of alternative methods of coping in exploring end-user satisfaction of electronic tablet PC-based high-stake exams.

\section{Background and related literature}

\subsection{Background of the study}

The present study explores the user perceptions of students enrolled in a private university, one among a few, in India on digitally enabled high stake handwritten examinations delivered through a custom-built paperless examination system on a tailor-made tablet computer. The University has already adopted this system originally developed by an Indian company as a comprehensive paperless exam solution. This was introduced as a logical extension of computer-based exam scripts evaluation already existing in the university. The new system would eliminate the tedious process of digitization of the paper-based answer scripts, as the answers are encrypted and captured in digitized format in real-time by the device. However, it is not clear how the end-users (students) perceive and react to this mandatory piece of radical technology introduced by the university, which fundamentally alters the way in which exams were previously conducted. Ultimately the end-user satisfaction is the benchmark against which the success of any technological intervention is measured. It is in this unique background that the current study explores the factors affecting the end-user satisfaction of this mandatory piece of radical technology touted to fundamentally change the handwritten exam experience.

\subsection{Paperless digital examination system}

The paperless digital examination system under consideration is an indigenously developed secure cloud-based ecosystem consisting of a customized software and purpose-built hardware (see Fig. 1) designed for conducting paperless hand-written examinations. The 'Exampad', i.e. the student side hardware unit, is a custom-built portable computer that enables students to write descriptive exams just as they would with a pen on paper. The device comes with an LCD touch screen display $(22.5 \times$ $14.5 \mathrm{~cm}$ ), a stylus pen, inbuilt fingerprint sensor, web camera, and WIFI and Bluetooth connectivity. The device runs on an Android 5.1 operating system and has a custom developed software application for conducting the examination. It allows exams to be written using integrated tools such as calculators, precisely calibrated geometric instruments, and various types of paper templates (plain, ruled, graph etc.). It also supports the use of multimedia and other rich content in the questions. Together, the cloud-based software ecosystem and the associated devices make the whole process of conducting the examinations, right from authoring the questions, conducting the tests, evaluating the answer scripts and publishing the results, completely digital and paperless.

The system eliminates common challenges involved in the administration of physical, paper-based descriptive exams, and offers a variety of unique benefits. Firstly, the access to the Exampad is restricted through a biometric system (fingerprint and retina scan) which prevents candidates' impersonation/cheating and ensures adequate data 


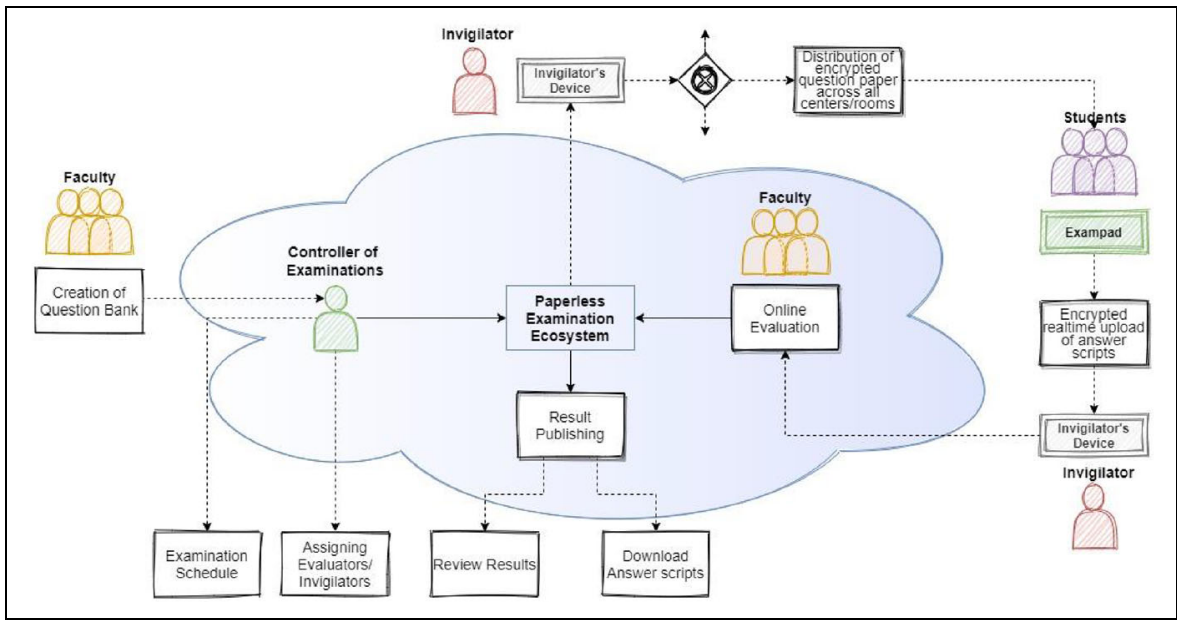

Fig. 1 Paperless digital examination ecosystem

security. Secondly, it reduces the turnaround time from question setting to result declaration by digitally enabled ubiquitous and transparent processes (e.g. online evaluations). Thirdly, it greatly simplifies the logistics of question paper and answer scripts through its mobile and scalable system. Fourthly, the ergonomically designed user interface (UI) and digital stylus ensures ease of use by providing virtually the same experience as the paper. Finally, it leaves a positive impact on the environment by eliminating the necessity of paper in the entire process. The platform is believed to support specialized examination requirements warranted by various discipline verticals and the varying institutional needs.

\subsection{Related literature}

Educational researchers (Shute et al. 2016; Siozos et al. 2009) have emphasized the role of technologically enhanced assessment tools to measure student competencies of current generation students. It has also been suggested as undebatable indicator of educational advancement (Hillier 2014). Computer-based assessments generate data on students' performance that may be further analysed by the teachers (Admiraal et al. 2020). Wass et al. (2020) found that students had a negative emotional response towards assessments and research on emotional response towards assessments is limited. Wass et al. (2020) recommend educators to take into account the emotional response of the students and their well-being, while planning the assessments.

There has been scarce literature on the impact of the increasing use of new technologies in assessment, on one of the important stakeholders, the students. In this study, we use coping theory to assess how students appraise the benefits and challenges of new technologies used in assessments. We also examine the coping strategies adopted by the students and their role in end-user satisfaction. End-user satisfaction is an important measure of information system success and is widely used by researchers and practitioners (Doll et al. 2004).

The research on new technology intervention and adoption has been fragmented (Beaudry and Pinsonneault 2005) and mainly deviated into two broad domains. The 
first domain focuses on the antecedents of technology adoption and has contributed many models (see Venkatesh et al. 2003). The second domain focuses on the process of technology adoption and explains the complex process of adoption and human interaction with new technology (Orlikowski 1996). Beaudry and Pinsonneault (2005) integrate both the domains of technology adoption and proposes a unified coping model of user adoption (CMUA). The CMUA defines the adoption process as 'coping' with new technology, as it offers a wider range of study opportunity in the form of modification in users' tasks, their emotional stability, user reaction, and adoption (Beaudry and Pinsonneault 2005).

\subsubsection{Coping theory and coping process}

Lazarus and Folkman (1984) proposed a model of coping that defines how a person appraises and acts on stressful events. Lazarus and Folkman (1984) define Coping as "the cognitive and behavioral efforts exerted to manage specific external and internal demands that are appraised as taxing or exceeding the resources of the person" (p. 141). The process of coping is divided into two major stages, which are interlinked (Lazarus 1966; Lazarus and Folkman 1984). In the first stage, when an individual encounters displacement by an event, he/she starts evaluating the consequences of the event. This process is defined as 'appraisal,' where the appraisal is associated with exploring the personal relevance of the event and its consequences, known as a primary appraisal (Folkman 1992). And, further, in the secondary appraisal, the individual evaluates the different coping strategies available based on the nature of the problem (Lazarus and Folkman 1984). The focus of the current study was a secondary appraisal, as we intended to examine which coping strategy would better explain the end-user satisfaction of computer-based exams.

In the second stage, the individual implements action to handle the situations, i.e., 'coping efforts.' The coping efforts are the combination of cognitive and behavioral efforts in the form of problem-focused coping and emotional-focused coping (Folkman 1992; Lazarus and Folkman 1984). A specific problem-focused coping deals with trying to alter the situation of dealing with the cause for displacement or altering the environment or change itself in terms of willingness to learn new skills (Lazarus and Folkman 1984). Emotional-Focused deals with altering the individual perception and try to deal with the change leading without altering the situation and to restore and maintain the stability (Lazarus and Folkman 1984). The coping efforts are characterized by different combinations of problem and emotion-focused, which has a greater chance of success and restore normalcy in the surrounding environment (Begley 1998). The process of coping is spread across timeframe segregated on psychological basis starts with anticipation period - before actual displacement occurs, impact period - occurrence of displacement and post-impact period - after the occurrence of the displacement (Folkman 1992).

Coping Model of User Adaptation (CMUA), proposed by Beaudry and Pinsonneault (2005), describes the process of user adaptation to information systems. The model posits that the user appraises the event as a threat and challenge and evaluates the degree of control (low or high). After the appraisal, the user adapts using problemfocused and emotion-focused coping methods. CMUA also identifies that user adaptation also leads to different outcomes such as increased efficiency, reduced negative 
perception of the situation, and restored emotional stability. Individuals put coping efforts, relying on their cognitive and behavioral efforts, and perform actions to deal with the situation (Lazarus and Folkman 1984). Problem-focused coping aims at managing the event by changing the environment or changing oneself (Beaudry and Pinsonneault 2005). It may include effort such as removing barriers, acquiring new knowledge and skills, and seeking assistance (Marakhimov and Joo 2017). Emotionfocused coping focuses on changes in one's perception of the situation. It aims at regulating personal emotions and tensions and minimizing the negative consequences of the threat (Beaudry and Pinsonneault 2005).

\subsubsection{End-user satisfaction}

End user-satisfaction is recognized as an appropriate surrogate to measure the effectiveness of the information system (Remenyi and Money 1991). User evaluations of information systems are important for IT managers to guide their decisions on adoption, implementation, and monitoring the effectiveness of information systems (Deng et al. 2008). Doll and Torkzadeh (1988) developed a EUCS instrument to measure Enduser satisfaction. EUCS is a second-order construct that uses five dimensions and 12 items to measure end-user satisfaction: Content, format, accuracy, ease of use, and timeliness (Doll and Torkzadeh 1988). EUCS has been widely used in research studies to measure user satisfaction with information systems applications (Abdinnour-Helm et al. 2005; Doll et al. 1994; Hou 2012). Deng et al. (2008) conducted a five-nation multivariate analysis on the instrument and found that EUCS measurement was equivalent across cultures. No studies are examining end-user satisfaction as an outcome in the coping process to the best of our knowledge. However, a metaanalytic study gives evidence of prior research on the relationship between system usage and user satisfaction (Bokhari 2005). System usage can be divided into the extent or magnitude of computer usage and its duration of use.

Previous studies, using coping theory, have examined several aspects of postadoption behavior such as technology infusion (Beaudry and Pinsonneault 2001; Fadel 2012b) and extended use (Po-An Hsieh and Wang 2007; Marakhimov and Joo 2017). Tarafdar et al. (2010) found that techno-stress reduces the satisfaction of individuals and mechanisms that facilitate user's involvement and diminish the factors that create techno-stress, and increases satisfaction. End-user satisfaction is one of the important outcomes of the post-adoption of information systems. In the present research, we explore the relationship between problem-focused and emotion-focused coping methods on end-user satisfaction. End-user satisfaction has been widely used as a measure to assess information system success. End-user satisfaction is defined as the satisfaction of students in using the technology-based assessment system. Based on these, the following hypotheses are proposed

H1: The extent of computer usage influences end-user satisfaction of technologyenabled assessment.

H2: The duration of computer usage influences end-user satisfaction of technology-enabled assessment.

H3: The interaction of extent of computer usage and its duration of use influences end-user satisfaction of technology-enabled assessment. 
H4: Problem-focused coping positively influences end-user satisfaction of technology-enabled assessment.

H5: Emotion-focused coping positively influences end-user satisfaction of technology-enabled assessment.

\section{Research methods}

\subsection{Approach}

The study followed an analytical method of inquiry to examine how the subjects appraised a critical situation that was coerced upon. The coping theory framework (Lazarus and Folkman 1984) complemented the research to comprehend the coping strategies to confront the situation and their transpiration into end-user satisfaction. We have made a pioneering attempt to capture the perception of students about the technology-intensive high-stake formative and summative examinations, using coping-theory. The approach of the study was a quantitative-oriented concurrent mixedmethod (Creswell and Clark 2007). Qualitative responses would be supplementary to quantitative inputs. The study explored the role of duration and extent of the computer on the relevant constructs of the study.

\subsection{Participants}

The input of the study was collected from 246 post-graduate students, with a gender proportion of $55 \%$ (male) and $45 \%$ (female). Though the students had prior experience with computers, they were first-timers in using such an innovative digital device, as an alternative to conventional pen-on-paper exams. The prospective respondents were contacted one-week after the end-of-term exam and invited to participate in the survey voluntarily through an email link. The respondents' gender was sought to examine any probable influence on perceiving the situation, coping, and end-user satisfaction.

\subsection{Items and measures}

The study instrument drew necessary items from Li et al. (2016), Duhachek (2005), Fadel (2012a, b) and Doll and Torkzadeh (1988). The End-user computing satisfaction (EUCS) instrument proposed by Doll and Torkzadeh (1988) was used to measure the satisfaction of the students in the study. It has proved to have adequate reliability and validity with several IT applications (Dastgir and Mortezaie 2012; Doll et al. 2004; Larsen 2009; Liu and Guo 2008; Marakarkandy and Yajnik 2013; Pikkarainen et al. 2006). The present study used an adapted 12 items EUCS instrument for measuring end-user satisfaction. All the items were reworded to suit the current technology and its features. Items are included in the annexure.

The items were measured on a five-point Likert scale to capture varying degrees of the agree-disagree continuum. All the items were made compulsory to enhance the response rate. Two open-ended questions were included in the survey instrument for eliciting deeper insights on satisfying and dissatisfying features of the device. These 
questions enabled the research team to capture varying aspects of user gratifications and apprehensions.

\subsection{Analytical method}

The main analytical tool of this study was MANCOVA using SPSS version 23. Multivariate analysis of covariance (MANCOVA) is a dependence technique that measures the differences for multiple dependent variables. Measured on the metric scale, based on a set of categorical variables acting as independent variables, controlling for other metric independent variables (Hair et al. 2014). The qualitative responses were coded thematically using QSR NVivo version10 using an inductive approach (Corbin and Strauss 1990).

\section{Results and analysis}

The five dimensions of end-user satisfaction (Doll and Torkzadeh 1988) were used as outcome variables. A theory-driven investigation was endeavoured to comprehend the role of the extent of computer usage (small, medium, and heavy) and duration of computer usage (up to five years, six to ten years, and above ten years) of the subjects as antecedents to end-user satisfaction from computer-based high-stake exams. The sub-dimension of end-user satisfaction (content, accuracy, format, ease of use, and timeliness) were retained as such to decipher the relative importance of statistically significant variances attributable to the outcome variables. Two metric variables (emotion-focused coping; EFC and problem-focused coping; PFC) were used as control variables (covariates).

We checked the assumptions of MANOVA (Field 2018; Hair et al. 2014) to ensure that the test procedures to be valid as a multivariate tool for data analysis. MANCOVA test procedures require five necessary assumptions: the absence of missing data, multivariate normality, the linearity of metric variables, homogeneity of variances and covariances, and homogeneity of error variance. Online surveys with the response to every item mandatory helped us to rule out missing data. A multivariate normality test was conducted for five outcome variables and two covariates using Mahalanobis distance (Field 2018). The test gave the minimum and maximum values as 1.030 and 22.058, respectively. Since the threshold value of Mahalanobis distance for seven degrees of freedom (five outcome variables and two covariates) and the $\rho$ value of 0.001 (the limit of probability value) is 24.32 , there is no violation of normality assumption and hence ruled out the presence of multivariate outliers in the data set. Matrix scatters plot was used to examine the linearity attribute of the metric variables. We observed the evidence of linearity for six variables, except timeliness (one of the dimensions of end-user satisfaction). Hence, six out of seven variables confirmed the requisite linearity trend. The test of homogeneity of variance and covariance is to confirm that the observed covariance matrices of the dependent variables are equal across the groups of categorical independent variables (Field 2018; Hair et al. 2014). The Box's test of equality of covariance matrices table recorded a $\rho$ value of 0.254 , which is higher than the threshold value of 0.001 to infer the null hypothesis is true (Field 2018; Hair et al. 2014). This has confirmed the homogeneity of variance- 
covariance assumption. The homogeneity of error variance assumption was tested using the Levene's test of equality of error variance. The test offered empirically non-significant results for all five dependent variables; all $\rho$ values were well above 0.05. This has confirmed the empirical evidence of the presence of equality of error variance of the dependent variable across the groups of independent variables.

Having confirmed the compliance of all necessary assumptions of MANCOVA test procedures to be valid, it was adopted as a major analytical tool of our study. Based on Field's (2018) advice Pillai's trace is the most robust multivariate test statistic when group sizes are dissimilar, homogeneity of variance-covariance assumption is not violated, and the assumption of multivariate normality is tenable. Using Pillai's trace, we observed an empirically non-significant effect of emotion-focused coping (EFC) on the five outcome variables of end-user satisfaction, as a group, $\mathrm{V}=0.02, \mathrm{~F}$ ( 5 , $231)=0.932, \rho>0.05$, with an effect size (partial Eta squared) of 0.02. Pillai's trace test statistic offered evidence of the statistically significant effect of problemfocused coping (PFC) on the outcome variables, as a group, $\mathrm{V}=0.05, \mathrm{~F}(5,231)=$ 2.397, $\rho<0.05$, with an effect size of 0.05 . Similarly, the extent of computer usage manifested exemplary empirical support to endorse its influence on the outcome variables, as a group, $\mathrm{V}=0.329, \mathrm{~F}(10,464)=9.144, \rho<0.001$, with an effect size of 0.17 . However, the effect of duration of computer usage on enduser satisfaction has turned out to be statistically insignificant as per Pillai's trace statistic, $\mathrm{V}=0.03, \mathrm{~F}(10,464)=0.787, \rho>0.05$, with an effect size of 0.02 . We also examined the interaction effect of usage extent of computers and its duration on the various dimensions of end-user satisfaction. The results of Pillai's trace test statistic failed to deliver statistically significant evidence on the interaction effect of two antecedents on perceived user satisfaction, $V=0.10, F(20,936)=1.101$, $\rho>0.05$, with an effect size of 0.02 . However, the multivariate test using Roy's largest root presented statistically significant result to infer interaction effect, = $0.05, \mathrm{~F}(5,234)=2.27, \rho<0.05$, with an effect size of 0.05 . the overall multivariate test using Pillai's trace confirmed the statistically significant effect of independent variables, as a group, on multiple dependent variables, $\mathrm{V}=0.33, \mathrm{~F}$ (10, $464)=9.144, \rho<0.001$, with an effect size of 0.17 .

On examining the main effects and interaction effects of the antecedents upon the outcome variables, the following information could be elicited from the test results, as evidenced from Table 1. Emotion-focused coping did not convey any empirical evidence to be the antecedent to user satisfaction. Problem-focused coping explicated its significant influence on user content and ease of use but failed to impress upon accuracy, format, and timeliness. We found that usage extent is the most significant factor as an antecedent to user satisfaction, with a single exception of timeliness. It is worth noting here that user satisfaction on timeliness is found attributable to none of its antecedents. Hence, it can be inferred that the outcome variable, timeliness, may not be as relevant as other end-user satisfaction aspects, as the data failed to fit into the theoretical construct well in the current study. The interaction effect also not much impressive, except for the outcome variable ease of use on a liberal measure. The tests of between-subjects' effects conferred moderate variances, except for timeliness; user satisfaction on content (40.5\%), User satisfaction on accuracy (39.0\%), user satisfaction on format $(41.7 \%)$, user satisfaction on ease of use $(34.8 \%)$, and user satisfaction on timeliness $(02.5 \%)$. 
Table 1 Tests of between-subjects effects

\begin{tabular}{|c|c|c|c|c|c|c|}
\hline \multirow[t]{2}{*}{ Source } & \multirow[t]{2}{*}{ Statistic } & \multicolumn{5}{|c|}{$\begin{array}{l}\text { Dependent Variables (Various aspects of User } \\
\text { satisfaction) }\end{array}$} \\
\hline & & Content $^{\mathrm{a}}$ & Accuracy ${ }^{b}$ & Format $^{\mathrm{c}}$ & $\begin{array}{l}\text { Ease of } \\
\text { Use }^{\mathrm{d}}\end{array}$ & Timeliness $^{\mathrm{e}}$ \\
\hline \multirow[t]{3}{*}{ Corrected Model } & $\mathrm{F}$ & 16.007 & 15.056 & 16.809 & 12.545 & .000 \\
\hline & Sig. & .000 & .000 & .000 & .602 & .812 \\
\hline & Partial Eta Squared & .405 & .390 & .417 & .348 & .025 \\
\hline \multirow[t]{3}{*}{ Intercept } & $\mathrm{F}$ & 101.607 & 55.304 & 95.634 & 29.963 & 93.392 \\
\hline & Sig. & .000 & .000 & .000 & .000 & .000 \\
\hline & Partial Eta Squared & .302 & .191 & .289 & .113 & .284 \\
\hline \multirow[t]{3}{*}{ EFC } & $\mathrm{F}$ & .345 & 3.121 & .096 & .569 & .047 \\
\hline & Sig. & .557 & .079 & .757 & .451 & .828 \\
\hline & Partial Eta Squared & .001 & .013 & .000 & .002 & .000 \\
\hline \multirow[t]{3}{*}{ PCF } & $\mathrm{F}$ & 3.820 & .790 & 1.012 & 8.246 & 1.070 \\
\hline & Sig. & .052 & .375 & .316 & .004 & .302 \\
\hline & Partial Eta Squared & .016 & .003 & .004 & .034 & .005 \\
\hline \multirow[t]{3}{*}{ Extent of computer usage } & $\mathrm{F}$ & 31.242 & 19.502 & 31.577 & 19.114 & .437 \\
\hline & Sig. & .000 & .000 & .000 & .000 & .646 \\
\hline & Partial Eta Squared & .210 & .142 & .212 & .140 & .004 \\
\hline \multirow[t]{3}{*}{ Duration of computer usage } & $\mathrm{F}$ & .019 & 2.834 & .090 & .507 & .501 \\
\hline & Sig. & .981 & .061 & .914 & .603 & .606 \\
\hline & Partial Eta Squared & .000 & .024 & .001 & .004 & .004 \\
\hline \multirow{3}{*}{$\begin{array}{l}\text { Extent } * \text { Duration } \\
\text { of computer usage }\end{array}$} & $\mathrm{F}$ & 1.928 & .527 & 1.386 & 2.324 & .251 \\
\hline & Sig. & .106 & .716 & .240 & .057 & .909 \\
\hline & Partial Eta Squared & .032 & .009 & .023 & .038 & .004 \\
\hline
\end{tabular}

\footnotetext{
a. $\mathrm{R}$ Squared $=.405$ (Adjusted R Squared $=.380$ )

b. R Squared $=.390$ (Adjusted R Squared $=.365$ )

c. R Squared $=.417$ (Adjusted R Squared $=.392$ )

d. $\mathrm{R}$ Squared $=.348$ (Adjusted R Squared $=.320$ )

e. R Squared $=.025$ (Adjusted R Squared $=-.017$ )

Source: Authors' own
}

We undertook a multiple comparisons test, for comparing the main effects of marginal means, using Bonferroni confidence interval adjustment, on computer usage extent, as it turned out to be a statistically significant explanatory variable of end-user satisfaction in the preliminary analysis. Multiple pairwise comparisons enabled us to compare average value of various relevant aspects of end-user satisfaction (content, accuracy, format, ease of use, and timeliness) across three levels of the extent of computer usage (low, medium, and high). The test results recorded statistically significant differences in the average user satisfaction across the extent of computer usage, except user satisfaction on timeliness (refer Table 2 for details). 
Table 2 Pairwise comparisons

\begin{tabular}{|c|c|c|c|c|c|c|c|}
\hline \multirow[t]{2}{*}{$\begin{array}{l}\text { Dependent } \\
\text { Variable }\end{array}$} & \multirow[t]{2}{*}{$\begin{array}{l}\text { (I) Extent of } \\
\text { computer } \\
\text { usage }\end{array}$} & \multirow[t]{2}{*}{$\begin{array}{l}\text { (J) Extent of } \\
\text { computer } \\
\text { usage }\end{array}$} & \multirow[t]{2}{*}{$\begin{array}{l}\text { Mean } \\
\text { Difference (I- } \\
\text { J) }\end{array}$} & \multirow[t]{2}{*}{$\begin{array}{l}\mathrm{S} \mathrm{t} \mathrm{d} \\
\text { Error }\end{array}$} & \multirow[t]{2}{*}{ Sig. ${ }^{b}$} & \multicolumn{2}{|c|}{$\begin{array}{l}95 \% \\
\text { Confidence } \\
\text { Interval for } \\
\text { Differenceb }^{b}\end{array}$} \\
\hline & & & & & & $\begin{array}{l}\text { Lower } \\
\text { Bound }\end{array}$ & $\begin{array}{l}\text { Upper } \\
\text { Bound }\end{array}$ \\
\hline \multirow{6}{*}{$\begin{array}{l}\text { User satisfaction on } \\
\text { content }\end{array}$} & \multirow[t]{2}{*}{ Low } & Medium & $-.779^{*}$ & .127 & .000 & -1.085 & -.473 \\
\hline & & Heavy & $-1.455^{*}$ & .191 & .000 & -1.917 & -.994 \\
\hline & \multirow[t]{2}{*}{ Medium } & Low & $.779^{*}$ & .127 & .000 & .473 & 1.085 \\
\hline & & Heavy & $-.677^{*}$ & .157 & .000 & -1.056 & -.297 \\
\hline & \multirow[t]{2}{*}{ Heavy } & Low & $1.455^{*}$ & .191 & .000 & .994 & 1.917 \\
\hline & & Medium & $.677^{*}$ & .157 & .000 & .297 & 1.056 \\
\hline \multirow{6}{*}{$\begin{array}{l}\text { User satisfaction on } \\
\text { Accuracy }\end{array}$} & \multirow[t]{2}{*}{ Low } & Medium & $-.527^{*}$ & .153 & .002 & -.896 & -.158 \\
\hline & & Heavy & $-1.442^{*}$ & .231 & .000 & -1.998 & -.885 \\
\hline & \multirow[t]{2}{*}{ Medium } & Low & $.527^{*}$ & .153 & .002 & .158 & .896 \\
\hline & & Heavy & $-.915^{*}$ & .190 & .000 & -1.372 & -.457 \\
\hline & \multirow[t]{2}{*}{ Heavy } & Low & $1.442^{*}$ & .231 & .000 & .885 & 1.998 \\
\hline & & Medium & $.915^{*}$ & .190 & .000 & .457 & 1.372 \\
\hline \multirow[t]{6}{*}{ User satisfaction on format } & \multirow[t]{2}{*}{ Low } & Medium & $-.877^{*}$ & .151 & .000 & -1.241 & -.513 \\
\hline & & Heavy & $-1.773^{*}$ & .228 & .000 & -2.322 & -1.223 \\
\hline & \multirow[t]{2}{*}{ Medium } & Low & $.877^{*}$ & .151 & .000 & .513 & 1.241 \\
\hline & & Heavy & $-.896^{*}$ & .187 & .000 & -1.347 & -.444 \\
\hline & \multirow[t]{2}{*}{ Heavy } & Low & $1.773^{*}$ & .228 & .000 & 1.223 & 2.322 \\
\hline & & Medium & $.896^{*}$ & .187 & .000 & .444 & 1.347 \\
\hline \multirow{6}{*}{$\begin{array}{l}\text { User satisfaction on Ease } \\
\text { of use }\end{array}$} & \multirow[t]{2}{*}{ Low } & Medium & $-.613^{*}$ & .170 & .001 & -1.023 & -.203 \\
\hline & & Heavy & $-1.585^{*}$ & .256 & .000 & -2.203 & -.967 \\
\hline & \multirow[t]{2}{*}{ Medium } & Low & $.613^{*}$ & .170 & .001 & .203 & 1.023 \\
\hline & & Heavy & $-.972^{*}$ & .211 & .000 & -1.481 & -.464 \\
\hline & \multirow[t]{2}{*}{ Heavy } & Low & $1.585^{*}$ & .256 & .000 & .967 & 2.203 \\
\hline & & Medium & $.972^{*}$ & .211 & .000 & .464 & 1.481 \\
\hline \multirow{6}{*}{$\begin{array}{l}\text { User satisfaction on } \\
\text { Timeliness }\end{array}$} & \multirow[t]{2}{*}{ Low } & Medium & -.154 & .183 & 1.000 & -.595 & .287 \\
\hline & & Heavy & -.042 & .276 & 1.000 & -.707 & .623 \\
\hline & \multirow[t]{2}{*}{ Medium } & Low & .154 & .183 & 1.000 & -.287 & .595 \\
\hline & & Heavy & .112 & .227 & 1.000 & -.435 & .659 \\
\hline & \multirow[t]{2}{*}{ Heavy } & Low & .042 & .276 & 1.000 & -.623 & .707 \\
\hline & & Medium & -.112 & .227 & 1.000 & -.659 & .435 \\
\hline
\end{tabular}

Based on estimated marginal means

*. The mean difference is significant at the .05 level

b. Adjustment for multiple comparisons: Bonferroni

Source: Authors' own 
We give, here, graphical presentation of main and interaction effects. Profile plots were used to depict those effects of the extent of computer usage and its duration on relevant aspects of user satisfaction. The extent of computer usage was depicted on the horizontal axis and mean satisfaction on the vertical axis. The duration of computer usage was represented by a separate line of the graph zone. Graphs were prepared separately for five outcome variables. The main effect of the extent of using tablet-PC was significant and explicit, as the marginal means of end-user satisfaction on content were significantly different across low, medium, and heavy users, as evident in Fig. 2. The differences in the marginal means of user satisfaction on content across the three groups of the duration of use were not as evident as that of the extent of use, indicating insignificant main effect.

The main effect of the extent of using the computer on the user satisfaction on accuracy depicted evidence of significant differences in its marginal means, as represented in Fig. 3. The low, medium, and high user intensities turned out to be consistent and coherent to attribute their effect on accuracy dimension of user satisfaction.

Similarly, the main effect of the extent of using a computer was statistically significant concerning end-user satisfaction on content, as the marginal means of low, medium, and heavy users were different across the groups, as depicted in Fig. 4. However, the main effect of the duration of computer use was not well explicit and significant upon end-user satisfaction on content.

Concerning the user satisfaction on ease of use, we observed a substantial difference in its marginal means against the extent of computer usage and a moderate difference about the duration of computer usage, as evidenced in Fig. 5. This result corroborates the results in Table 1. It can be inferred from this result that both the frequency of use and duration of use enables the students to take up high-stake computer-based exams at ease.

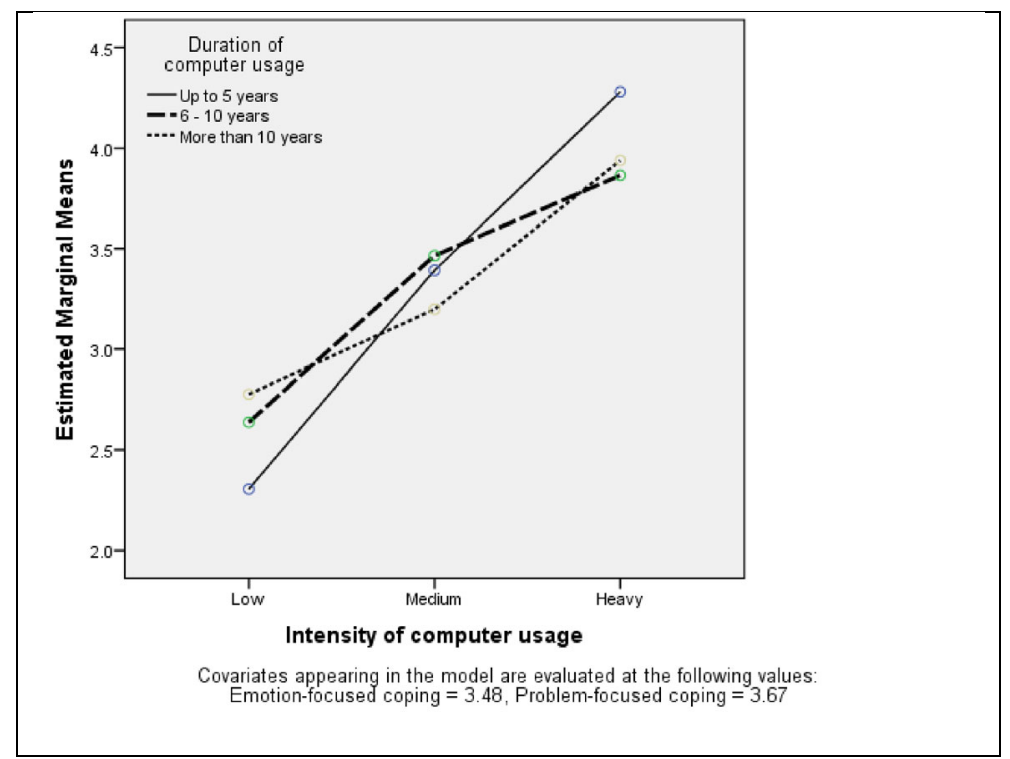

Fig. 2 Main \& interaction effect of user satisfaction on content 


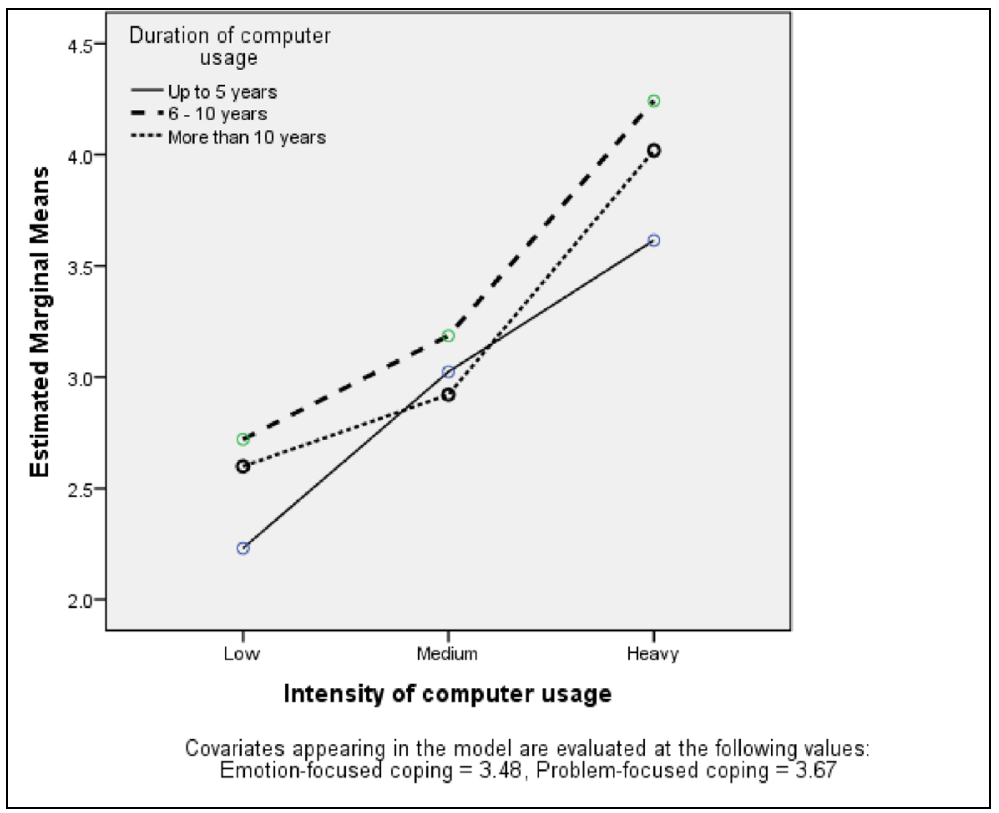

Fig. 3 Main \& interaction effect of user satisfaction on accuracy

Consistent with the previous result (refer Table 1), the profile plot user satisfaction on timeliness does not indicate a coherent main effect of either extent of computer usage of its duration of use, as depicted in Fig. 6. The time dimension need not be theoretically robust concerning the respondents of this study.

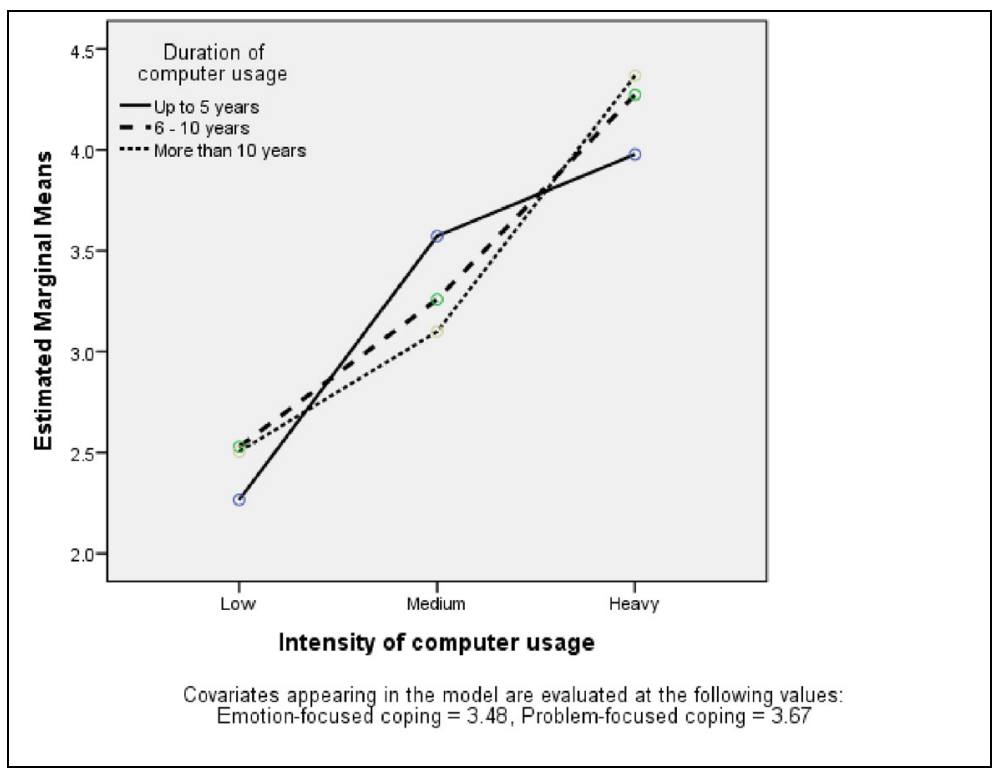

Fig. 4 Main \& interaction effect of user satisfaction on format 


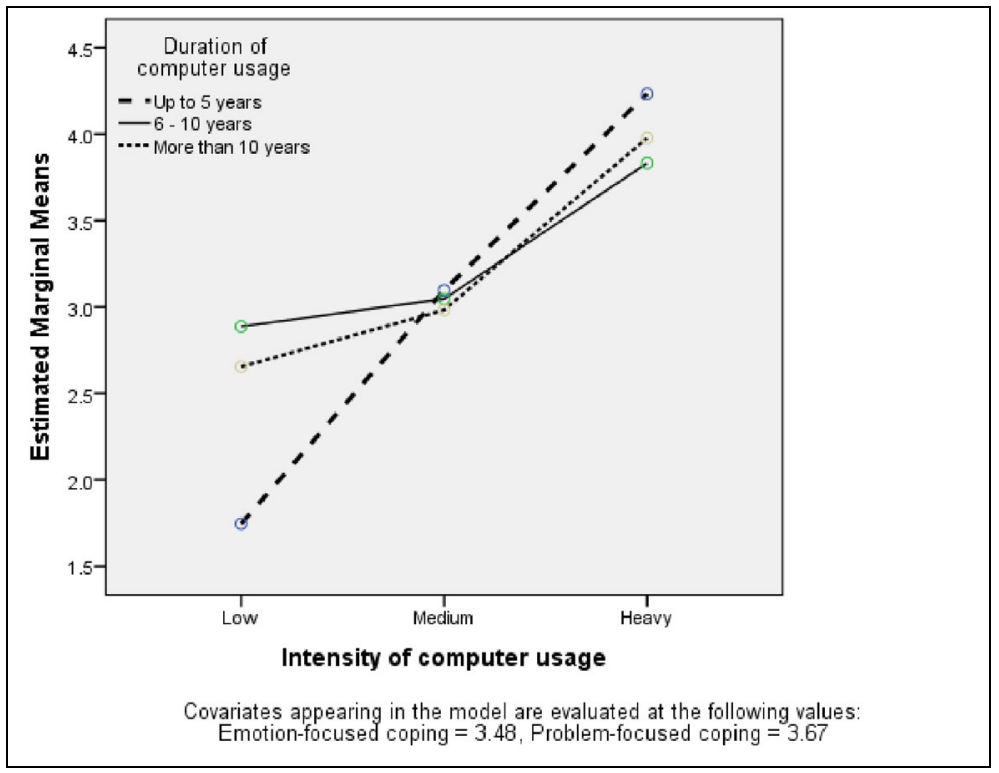

Fig. 5 Main \& interaction effect of user satisfaction on ease of use

As a pioneering attempt to comprehend the level of satisfaction of students on the technology embedded exam device, we prompted them to unfold satisfying and dissatisfying features of the device using two open-ended questions. An inductive analysis, using Nvivo software, helped us elicite emergent themes from the qualitative responses towards satisfying and dissatisfying features. Such themes, with their subthemes and sample excerpts, are presented in Table 3. The analysis of responses against

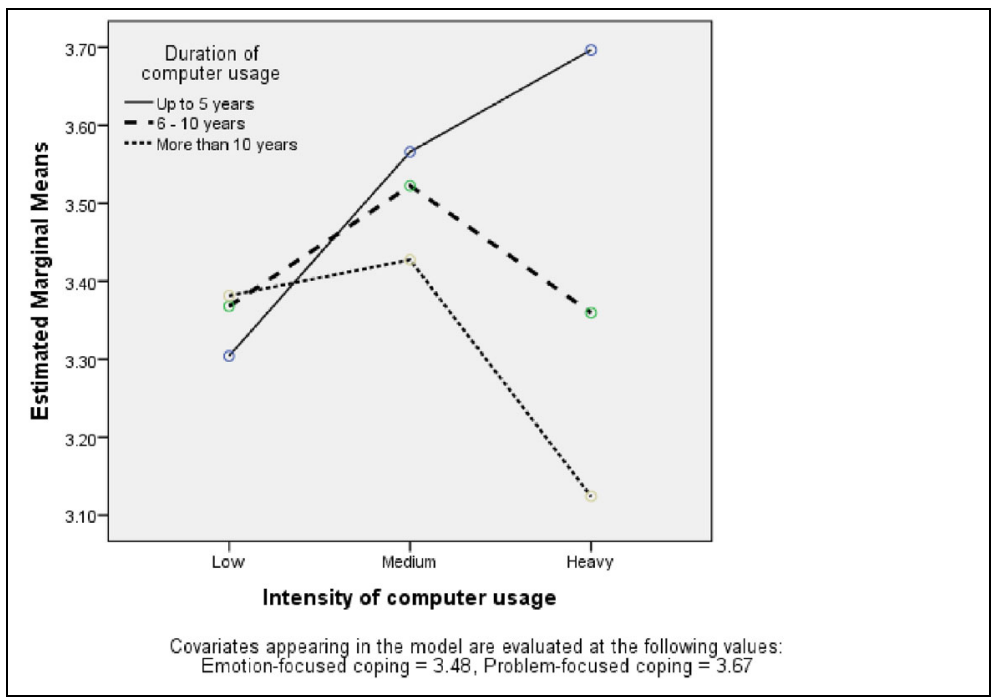

Fig. 6 Main \& interaction effect of user satisfaction on timeliness 
Table 3 Emergent themes of satisfying and dissatisfying features of exam device

\begin{tabular}{|c|c|c|c|}
\hline \multicolumn{4}{|l|}{ Satisfying Features } \\
\hline Theme & Sub-theme & Frequency & Sample Excerpt \\
\hline \multirow{2}{*}{$\begin{array}{l}\text { Environment-friendly } \\
\quad \text { model }\end{array}$} & Environment-friendly & 33 & "Eco-friendly as there is no wastage of paper." \\
\hline & $\begin{array}{l}\text { Reduces the usage of } \\
\text { stationary }\end{array}$ & 5 & "Exams without using any stationary material!" \\
\hline Convenience & Convenience & 26 & $\begin{array}{l}\text { "Very convenient as we do not have to carry } \\
\text { anything to the hall or be worried about any } \\
\text { exam materials required if we forget to } \\
\text { bring." }\end{array}$ \\
\hline \multirow[t]{2}{*}{$\begin{array}{l}\text { Novel Digital } \\
\text { Features }\end{array}$} & $\begin{array}{l}\text { Mistake correction } \\
\text { feature }\end{array}$ & 36 & $\begin{array}{l}\text { "The ability to easily edit mistakes and modify } \\
\text { answers as this is not easily possible in a } \\
\text { paper-based test." }\end{array}$ \\
\hline & $\begin{array}{l}\text { Drawing tools, } \\
\text { highlighter, } \\
\text { calculator features }\end{array}$ & 51 & $\begin{array}{l}\text { "Provision of various tools like graph sheets, } \\
\text { calculator, colour options, font options, etc. } \\
\text { are handy." } \\
\text { "Reduces the efforts of drawing tables and } \\
\text { charts which was difficult in the traditional } \\
\text { method." }\end{array}$ \\
\hline Time management & $\begin{array}{l}\text { Facilitates better time } \\
\text { allocation }\end{array}$ & 17 & $\begin{array}{l}\text { "It was helping me to allocate my time for } \\
\text { answering." }\end{array}$ \\
\hline \multicolumn{4}{|l|}{ Dissatisfying Features } \\
\hline Writing Quality & $\begin{array}{l}\text { Deteriorates quality } \\
\text { and speed of } \\
\text { handwriting }\end{array}$ & 115 & $\begin{array}{l}\text { "I was surprised by how bad my handwriting is } \\
\text { on the exam pad." } \\
\text { "My handwriting went bad, and writing speed is } \\
\text { slow." }\end{array}$ \\
\hline \multirow[t]{4}{*}{ Technical issues } & $\begin{array}{l}\text { Difficulty in } \\
\text { navigation }\end{array}$ & 37 & $\begin{array}{l}\text { "Extremely difficult to navigate between } \\
\text { question paper and answer sheets." } \\
\text { "One has to give more time in adjusting and } \\
\text { scrolling rather than focusing on answering" }\end{array}$ \\
\hline & $\begin{array}{l}\text { Stylus and calibration } \\
\text { issues }\end{array}$ & 31 & $\begin{array}{l}\text { "Stylus needs to be calibrated most of the time." } \\
\text { "The stylus is not very responsive." }\end{array}$ \\
\hline & System hang/lag & 83 & $\begin{array}{l}\text { "Opening a new question after solving one takes } \\
\text { a lot of time." } \\
\text { "On a few occasions while answering the exam, } \\
\text { the system crashed on its own and whatever } \\
\text { has been written got erased." }\end{array}$ \\
\hline & $\begin{array}{l}\text { Usability of features } \\
\text { (like drawing tool, } \\
\text { calculator) }\end{array}$ & 51 & $\begin{array}{l}\text { "Certain features like using graph sheets and } \\
\text { calculators were trouble." }\end{array}$ \\
\hline \multirow[t]{3}{*}{$\begin{array}{l}\text { Health-related } \\
\text { concerns }\end{array}$} & Eye-straining & 11 & $\begin{array}{l}\text { "I had a lot of eye irritation after writing the } \\
\text { exam on the device for continuous three } \\
\text { hours." }\end{array}$ \\
\hline & $\begin{array}{l}\text { Increases anxiety and } \\
\text { stress }\end{array}$ & 11 & $\begin{array}{l}\text { "Not at all a beneficial for the student it gives } \\
\text { them more pressure and stress during exams. } \\
\text { Exams I wrote using exam pad were the most } \\
\text { uncomfortable exams I ever wrote in my life." }\end{array}$ \\
\hline & Hand Fatigue/Pain & 11 & $\begin{array}{l}\text { "The hard surface of the screen, which makes it } \\
\text { hard to write." } \\
\text { "Hand starts hurting later." }\end{array}$ \\
\hline \multirow[t]{2}{*}{ Design related issues } & $\begin{array}{l}\text { Non-Ergonomic } \\
\text { design }\end{array}$ & 4 & $\begin{array}{l}\text { "Shape and size of the exam pad is not } \\
\text { ergonomic." }\end{array}$ \\
\hline & $\begin{array}{l}\text { User interface and } \\
\text { display related } \\
\text { issues }\end{array}$ & 7 & $\begin{array}{l}\text { "Very less space on display to solve statistical } \\
\text { or accounting problems." }\end{array}$ \\
\hline
\end{tabular}

Source: Authors' own 
satisfying features extracted four themes and six sub-themes. Similarly, the dissatisfying features were grouped into four themes and ten sub-themes.

\section{Discussions and managerial implications}

The current study visualizes a unique social context, where the mandatory IT use is enforced upon users similar to the works of Venkatesh et al. (2003), Koh et al. (2010), and Bhattacherjee et al. (2018). Even in mandatory setting studies, the users considered for the study are drawn from a heterogeneous background in terms of age, experience, and previous exposure to IT systems (Bhattacherjee et al. 2018). On the contrary, this study examined a highly homogeneous users' sample in term of age and levels of cognition. Thus, the context in which the study is carried out helped us eliminate the limitations of research design and achieve methodological rigor, owing to more likelihood of convergence of study findings.

The results of this study indicate that problem-focused coping has a significant influence on end-user satisfaction, and this relationship is positively endorsed by the extent of computer usage. This finding was in contrast with past studies (Beaudry and Pinsonneault 2001, 2005; Fadel 2012a; Marakhimov and Joo 2017), which posit that problem-focused coping has more impact on user satisfaction and adoption of information technology system. This result is theoretically coherent, as problem-focused coping attempts to address a disruptive event by changing the environment or changing one's self (Lazarus and Folkman 1984). In this process of coping, the students who find the unprecedented exposure a disruptive event, and, hence, may find new resources, or seek help, or learning a new skill to adapt rather than resent or withdraw. Lazarus and Folkman (1984) have claimed that problem-focused coping occurs when the subjects feel that the disruptive vent is within their control. It appears to be logically congruent that the respondents to our survey were well exposed to computers, which can quickly adapt to a similar environment with practice and scaffolding.

Fadel $(2012 \mathrm{a}, \mathrm{b})$ suggests that problem-focused coping is a strong predictor of user adoption than emotion-focused coping. We found that emotion-focused coping did not have an impact on end-user satisfaction. Extending this argument out findings reveals that emotion-focused coping is insignificant in predicting end-user satisfaction of information technology embedded exams. We further seek to explain this behavior as our sample constitute the majority (210 out of 246) of computers and IT system users from more than five-year period, which adds to the comfortable adoption of IT systems. Further, the previous usage will add to an affinity for technology (Franke et al. 2019). This is supported by the increasing digital transformation at the macro level and its impact on the young generation (Kompen et al. 2019).

Most of the studies on IT system adoption models are developed based on the studies conducted in an organizational context. Thus, based on our findings, we argue that IT infusion in higher education context differs from organizational context as well as we also suggest how information technology adoption and satisfaction differ in the higher education context. 


\subsection{Implications of the study}

As the IT applications are taking center stage in a higher education setting, our study will act as a guide for designers and facilitate a clear understanding of end-user satisfaction among higher education users. The findings indicate problem-focused coping with having a significant influence on end-user satisfaction in a mandatory technology environment. Educators can simplify the coping process for students by providing adequate training in the electronic exam device and reduce techno-stress during the exams. As problem-focused coping primarily involves developing skills to adapt to the new situation, adequate practice sessions with the mock test would also be useful. Technical assistance must be ensured during the exams for their smooth administration and assuring students of the technical support system. This would enable the students to focus only on the subject of the exam and not the technical aspects of the device. The introduction of electronic exams in the HEIs requires adequate technical support staff for the smooth conduct of the exams. The students without adequate IT experience in mandatory technology environments may face higher levels of stress, which may be reduced through handholding and confidence-building measures. The extracted themes, with sub-themes and excerpts from the responses of satisfying and dissatisfying feature, can offer managerial insights for further calibration of the device.

\section{Conclusion}

The infusion of technology into education has brought about groundbreaking innovations in learning and assessment processes across the world. In India, though, the use of technology in assessment processes is still in the nascent stage. Even though technology adoption in assessment processes is slowly gaining prominence among some higher education institutions in the country, the majority of the institutions are found to delay this technological leverage for want of necessary calibration in the devices, with a slew of perceived apprehensions of likely technical snags and failures. Another contributing factor also relates to the possible apprehensions and discomfort that students may experience towards such technological interventions in exam and assessment processes. This is because some students who may have never been exposed to such experiences may be more reluctant to use it as it is unprecedented to them. Deciphering the level of end-user satisfaction is an unarguable prerequisite for the developers and vendors to redesign the device to cater to the emerging needs of its users. The implementing institutions will also find it useful, such as information, to reiterate the effectiveness of academic outcome assessment.

Funding Open access funding provided by Manipal Academy of Higher Education, Manipal.

\section{Annexure: Constructs and measures}

\section{Problem-focused coping}

PFC1. I am ready to take technical support available on-site to solve the difficulties using technology-enabled assessment. 
PFC2. I am ready to put some effort on exploring new ways to improve familiarity with the device.

PFC3. I am ready to put some effort on exploring various new ways to improve functional efficiency with the device.

PFC4. I am ready to put some effort on practicing repetitively on mock exams.

\section{Emotion-focused coping}

EFC1. I try to overlook disadvantages of technology-enabled assessment.

EFC2. I try to focus on benefits I get from using technology-enabled assessment. EFC3. I try to make the best of what the device offers.

EFC4. I try to change my mind about technology-enabled assessment to positive and make exam experience enjoyable.

\section{End-user satisfaction}

\section{Content}

EUSC1. The questions displayed in technology-enabled assessment is precise.

EUSC2. The menu options provided in technology-enabled assessment system meet my exam needs.

EUSC3. The technology-enabled assessment contains sufficient information to write answers.

EUSC4. Faculty evaluation feed-back enabled in technology-enabled assessment system meet my needs.

\section{Accuracy}

EUSA1. Technology-enabled assessment system is accurate.

EUSA2. I am satisfied with the accuracy of the technology-enabled assessment system.

\section{Format}

EUSF1. I think the output is presented in the useful format.

EUSA2. I think information in the system is clear.

\section{Ease of use}

EUSE1. Technology-enabled assessment system is user friendly.

EUSE2. Technology-enabled assessment system answer sheet is easy to use. 


\section{Timeliness}

EUST1. Technology-enabled assessment needs only minimal booting time. EUST2. The Technology-enabled assessment will freeze the time lost due to technical snag, during exams.

Open Access This article is licensed under a Creative Commons Attribution 4.0 International License, which permits use, sharing, adaptation, distribution and reproduction in any medium or format, as long as you give appropriate credit to the original author(s) and the source, provide a link to the Creative Commons licence, and indicate if changes were made. The images or other third party material in this article are included in the article's Creative Commons licence, unless indicated otherwise in a credit line to the material. If material is not included in the article's Creative Commons licence and your intended use is not permitted by statutory regulation or exceeds the permitted use, you will need to obtain permission directly from the copyright holder. To view a copy of this licence, visit http://creativecommons.org/licenses/by/4.0/.

\section{References}

Abdinnour-Helm, S. F., Chaparro, B. S., \& Farmer, S. M. (2005). Using the end-user computing satisfaction (EUCS) instrument to measure satisfaction with a web site. Decision Sciences, 36(2), 341-364.

Abouserie, R. (1996). Stress, coping strategies and job satisfaction in university academic staff. Educational Psychology, 16(1), 49-56.

Admiraal, W., Vermeulen, J., \& Bulterman-Bos, J. (2020). Teaching with learning analytics: How to connect computer-based assessment data with classroom instruction? Technology, Pedagogy and Education, 115. https://doi.org/10.1080/1475939X.2020.1825992.

Alquraan, M. F. (2014). A cross-cultural study of students' perceptions of assessment practices in higher education. Education, Business \& Society: Contemporary Middle Eastern Issues, 7(4), 293-315.

Ball, D. M., \& Levy, Y. (2008). Emerging educational technology: Assessing the factors that influence Instructors' acceptance in information systems and other classrooms. Journal of Information Systems Education, 19(4), 431-444.

Beaudry, A., \& Pinsonneault, A. (2001). IT-induced adaptation and individual performance: A coping acts model. In V. Storey, S. Sarkar, \& J. I. DeGross (Eds.), Proceedings of the 22nd international conference on information systems (pp. 475-479). New Orleans.

Beaudry, A., \& Pinsonneault, A. (2005). Understanding user responses to information technology: A coping model of user adaptation. MIS Quarterly, 29(3), 493-524.

Begley, T. M. (1998). Coping strategies as predictors of employee distress and turnover after an organizational consolidation: A longitudinal analysis. Journal of Occupational and Organizational Psychology, 71(4), 305-329.

Bennett, R. E. (2006). Inexorable and inevitable: The continuing story of technology and assessment. Computer-based testing and the internet: Issues and advances, 1(1), 201-217.

Bhattacherjee, A., Davis, C. J., Connolly, A. J., \& Hikmet, N. (2018). User response to mandatory IT use: A coping theory perspective. European Journal of Information Systems, 27(4), 395-414.

Bokhari, R. H. (2005). The relationship between system usage and user satisfaction: A meta-analysis. Journal of Enterprise Information Management, 18(2), 211-234.

Chan, K. K. (2018). The effect of teachers' perceptions on the role of technology in assessment: The case of Macau. International Journal of Learning, Teaching and Educational Research, 17(2), 127-137.

Corbin, J. M., \& Strauss, A. (1990). Grounded theory research: Procedures, canons, and evaluative criteria. Qualitative Sociology, 13(1), 3-21.

Creswell, J. W., \& Clark, P. V. L. (2007). Designing and conducting mixed methods research. Thousand Oaks: Sage.

Dastgir, M., \& Mortezaie, A. S. (2012). Factors affecting the end-user computing satisfaction. Business Intelligence Journal, 5(2), 292-298. 
Deng, X., Doll, W. J., Al-Gahtani, S. S., Larsen, T. J., Pearson, J. M., \& Raghunathan, T. S. (2008). A crosscultural analysis of the end-user computing satisfaction instrument: A multi-group invariance analysis. Information \& Management, 45(4), 211-220.

Denton, P., Madden, J., Roberts, M., \& Rowe, P. (2008). Students' response to traditional and computerassisted formative feedback: A comparative case study. British Journal of Educational Technology, 39(3), 486-500.

Dermo, J. (2009). E-assessment and the student learning experience: A survey of student perceptions of eassessment. British Journal of Educational Technology, 40(2), 203-214.

Doll, W. J., \& Torkzadeh, G. (1988). The measurement of end-user computing satisfaction. MIS Quarterly, 12(2), 259-274.

Doll, W. J., Xia, W., \& Torkzadeh, G. (1994). A confirmatory factor analysis of the end-user computing satisfaction instrument. MIS Quarterly, 18(4), 357-369.

Doll, W. J., Deng, X., Raghunathan, T. S., Torkzadeh, G., \& Xia, W. (2004). The meaning and measurement of user satisfaction: A multi-group invariance analysis of the end-user computing satisfaction instrument. Journal of Management Information Systems, 21(1), 227-262.

Duhachek, A. (2005). Coping: A multidimensional, hierarchical framework of responses to stressful consumption episodes. Journal of Consumer Research, 32(1), 41-53.

Fadel, K. J. (2012a). The role of appraisal in adapting to information systems. Journal of Organizational and End User Computing, 24(4), 18-40.

Fadel, K. J. (2012b). User adaptation and infusion of information systems. Journal of Computer Information Systems, 52(3), 1-10.

Field, A. (2018). Discovering statistics using IBM SPSS statistics (5th ed.). Thousand Oaks, CA: Sage.

Folkman, S. (1992). Making the case for coping. In B. N. Carpenter (Ed.), Personal coping: Theory, research, and application (1st ed., pp. 31-46). Westport: Praeger.

Frank, M., \& Barzilai, A. (2004). Integration alternative assessment in a project based learning course and technology teachers. Assessment and Evaluation in Higher Education, 29(1), 41-61.

Franke, T., Attig, C., \& Wessel, D. (2019). A personal resource for technology interaction: Development and validation of the affinity for technology interaction (ATI) scale. International Journal of HumanComputer Interaction, 35(3), 456-467.

Gotlib, J., Panczyk, M., Gębski, P., Zarzeka, A., Iwanow, L., Dąbrowski, F., Dykowska, G., \& Malczyk, M. (2015). Comparative analysis of opinions of Warsaw Medical University students on electronic examinations and final tests by their participation in this form of knowledge assessment-preliminary report. Polish Journal of Public Health, 125(3), 153-158.

Griffith, J., Steptoe, A., \& Cropley, M. (1999). An investigation of coping strategies associated with job stress in teachers. British Journal of Educational Psychology, 69(4), 517-531.

Groomes, D. A., \& Leahy, M. J. (2002). The relationships among the stress appraisal process, coping disposition, and level of acceptance of disability. Rehabilitation Counseling Bulletin, 46(1), 14-23.

Hair, J. F., Black, W. C., Babin, B. J., \& Anderson, R. E. (2014). Multivariate data analysis: Pearson new international edition. Essex: Pearson Education Limited.

Harzer, C., \& Ruch, W. (2015). The relationships of character strengths with coping, work-related stress, and job satisfaction. Frontiers in Psychology, 6, 1-12.

Healy, C. M., \& McKay, M. F. (2000). Nursing stress: The effects of coping strategies and job satisfaction in a sample of Australian nurses. Journal of Advanced Nursing, 31(3), 681-688.

Hillier, M. (2014). The very idea of e-exams: Student (pre) conceptions. In Proceedings of ASCILITE 2014Annual Conference of the Australian Society for Computers in Tertiary Education (pp. 77-88).

Hillier, M. \& Fluck, A. (2013). Arguing again for e-exams in high stakes examinations. In Proceedings of Electric Dreams. Proceedings ASCILITE 2013 Sydney (pp. 385-396). Australasian Society for Computers in learning in tertiary education. Retrieved from https://www.learntechlib.org/p/171153/.

Hou, C. K. (2012). Examining the effect of user satisfaction on system usage and individual performance with business intelligence systems: An empirical study of Taiwan's electronics industry. International Journal of Information Management, 32(6), 560-573.

Hu, P. J. H., Clark, T. H., \& Ma, W. W. (2003). Examining technology acceptance by school teachers: A longitudinal study. Information \& Management, 41(2), 227-241.

Koh, C. E., Prybutok, V. R., Ryan, S. D., \& Wu, Y. (2010). A model for mandatory use of software technologies: An integrative approach by applying multiple levels of abstraction. Informing Science: The International Journal of an Emerging Transdiscipline, 13, 177-203.

Kompen, R. T., Edirisingha, P., Canaleta, X., Alsina, M., \& Monguet, J. M. (2019). Personal learning environments based on web 2.0 services in higher education. Telematics and Informatics, 38, 194-206. 
Larsen, T. J. (2009). A multilevel explanation of end-user computing satisfaction with an enterprise resource planning system within an international manufacturing organization. Computers in Industry, 60(9), 657668.

Lazarus, R. S. (1966). Psychological stress and the coping process. Albany: McGraw-Hill.

Lazarus, R. S., \& Folkman, S. (1984). Stress, appraisal, and coping. Albany: Springer Publishing Company.

Li, H., Wu, J., Gao, Y., \& Shi, Y. (2016). Examining individuals' adoption of healthcare wearable devices: An empirical study from privacy calculus perspective. International Journal of Medical Informatics, 88, 817.

Lin, C. C. (2016). The roles of social support and coping style in the relationship between gratitude and wellbeing. Personality and Individual Differences, 89, 13-14.

Liu, C. T., \& Guo, Y. M. (2008). Validating the End-User Computing Satisfaction Instrument for Online Shopping Systems. Journal of Organizational \& End User Computing, 20(4), 74-96.

Long, B. C. (1993). Coping strategies of male managers: A prospective analysis of predictors of psychosomatic symptoms and job satisfaction. Journal of Vocational Behavior, 42(2), 184-199.

Marakarkandy, B., \& Yajnik, N. (2013). Re-examining and empirically validating the End User Computing Satisfaction models for satisfaction measurement in the internet banking context. International Journal of Bank Marketing, 31(6), 440-455.

Marakhimov, A., \& Joo, J. (2017). Consumer adaptation and infusion of wearable devices for healthcare. Computers in Human Behavior, 76, 135-148.

Orlikowski, W. J. (1996). Improvising organizational transformation over time: A situated change perspective. Information Systems Research, 7(1), 63-92.

Pikkarainen, K., Pikkarainen, T., Karjaluoto, H., \& Pahnila, S. (2006). The measurement of end-user computing satisfaction of online banking services: empirical evidence from Finland. International Journal of Bank Marketing., 24(2), 158-172.

Po-An Hsieh, J. J., \& Wang, W. (2007). Explaining employees' extended use of complex information systems. European Journal of Information Systems, 16(3), 216-227.

Remenyi, D., \& Money, A. (1991). A user-satisfaction approach to IS effectiveness measurement. Journal of Information Technology, 6(3), 162-175.

Rouseff-Baker, F., \& Holm, A. (2004). Engaging faculty and students in classroom assessment of learning. New Directions for Community Colleges, 126, 29-42.

Sequeira, C. (2013). Difficulties, coping strategies, satisfaction and burden in informal Portuguese caregivers. Journal of Clinical Nursing, 22(3-4), 491-500.

Shute, V. J., Leighton, J. P., Jang, E. E., \& Chu, M. W. (2016). Advances in the science of assessment. Educational Assessment, 21(1), 34-59.

Siozos, P., Palaigeorgiou, G., Triantafyllakos, G., \& Despotakis, T. (2009). Computer based testing using "digital ink": Participatory design of a tablet PC based assessment application for secondary education. Computers \& Education, 52(4), 811-819.

Tarafdar, M., Tu, Q., \& Ranga-Nathan, T. (2010). Impact of Technostress on end-user satisfaction and performance. Journal of Management Information Systems, 27(3), 303-334.

Thelwall, M. (2000). Computer-based assessment: A versatile educational tool. Computers \& Education, 34(1), 37-49.

Venkatesh, V., Morris, M. G., Davis, G. B., \& Davis, F. D. (2003). User acceptance of information technology: Toward a unified view. MIS Quarterly, 27(3), 425-478.

Wass, R., Timmermans, J., Harland, T., \& McLean, A. (2020). Annoyance and frustration: Emotional responses to being assessed in higher education. Active Learning in Higher Education, 21(3), 189-201. https://doi.org/10.1177/1469787418762462.

Publisher's note Springer Nature remains neutral with regard to jurisdictional claims in published maps and institutional affiliations. 


\section{Affiliations}

K. R. Pillai ${ }^{1}$ - Pallavi Upadhyaya ${ }^{1} \cdot$ Ashish Viswanath Prakash ${ }^{2} \cdot$ Badrinarayan $^{2}$ Srirangam Ramaprasad ${ }^{3} \cdot$ H. V. Mukesh ${ }^{4} \cdot$ Yogesh Pai $^{1}$

Pallavi Upadhyaya

pallavi.upd@manipal.edu

Ashish Viswanath Prakash

ashishviswanathprakash@gmail.com

Badrinarayan Srirangam Ramaprasad

sr.badrinarayan@gmail.com

H. V. Mukesh

mukesh.hv@manipal.edu

Yogesh Pai

yogesh.pai@manipal.edu

1 Manipal Institute of Management, Manipal Academy of Higher Education, Manipal, Karnataka 576104, India

2 Vinod Gupta School of Management, Indian Institute of Technology, Kharagpur, West Bengal 721302, India

3 Justice K. S. Hedge Institute of Management, NITTE, Mangalore, India

4 Department of Commerce, Manipal Academy of Higher Education, Manipal, Karnataka 576104, India 